Document downloaded from:

http://hdl.handle.net/10251/60257

This paper must be cited as:

Torregrosa, AJ.; Broatch, A.; Olmeda, P.; Cornejo, O. (2014). Experiments on subcooled flow boiling in I.C. engine-like conditions at low flow velocities. Experimental Thermal and Fluid Science. 52:347-354. doi:10.1016/j.expthermflusci.2013.10.004.

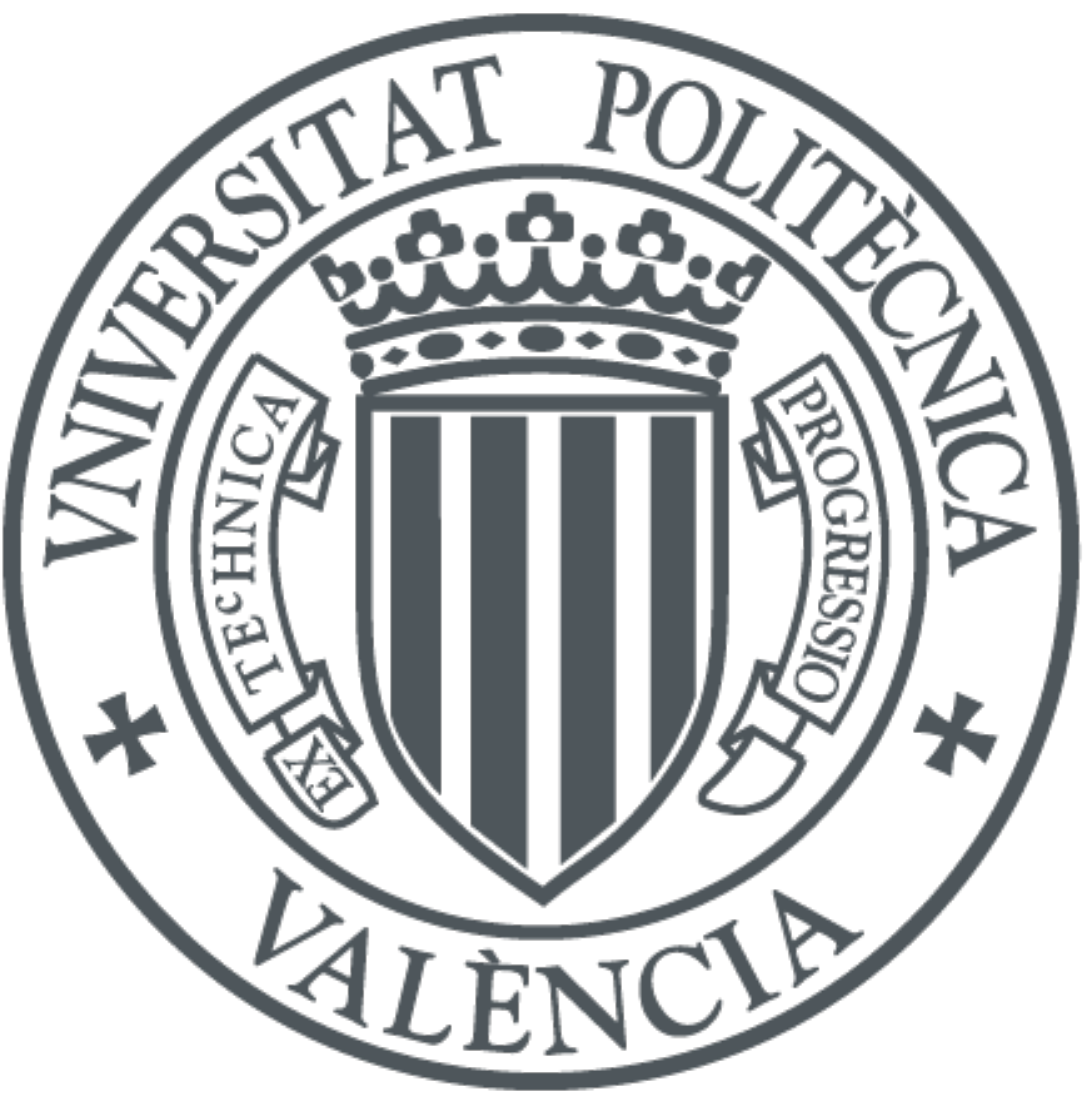

The final publication is available at

http://dx.doi.org/10.1016/j.expthermflusci.2013.10.004

Copyright Elsevier

Additional Information 


\title{
Experiments on subcooled flow boiling in I.C. engine-like conditions at low flow velocities
}

\author{
A.J. Torregrosa*, A. Broatch, P. Olmeda, O. Cornejo \\ CMT - Motores Térmicos, Universitat Politècnica de València, Aptdo. 22012, E-46071 Valencia, Spain.
}

\begin{abstract}
Subcooled boiling flow is specially attractive for engine cooling system design, as no essential changes in its architecture are required while it is still possible to take advantage of the highest rates of heat transfer associated with nucleate boiling, mostly at high engine loads. In this paper, experiments on subcooled boiling flow in representative temperature conditions were conducted with a usual engine coolant in the low velocity range, for which little information is available, even if it may be relevant when advanced thermal management strategies are used. The results were analyzed by comparison with a reference Chen-type model which provided reasonable results for relatively low wall temperatures, but with noticeable discrepancies at higher wall temperatures. Analysis of the deviations observed indicated a significant influence of the Prandtl number on the suppression factor, and the inclusion into the model of a first estimate of this effect produced a noticeable improvement in its results, thus suggesting that one such modified additive model may be useful for practical engine cooling applications.
\end{abstract}

Keywords: Engine cooling, Subcooled flow boiling, Suppression factor, Prandtl number

\section{Introduction}

Internal combustion engines are currently facing two concurrent requirements: fuel consumption and emissions must be reduced while performance should not be penalized [1]. While different possibilities may allow to achieve these goals [2], manufacturers are specially interested in engine downsizing. However, among other problems a serious issue associated with this technical solution is heat transfer, since the implied increase in the relative heat losses, together with the observed changes in their spatial distribution [3] actually pose intrinsic limitations to the engine size limits [4]. Additionally, the potential benefits of the use of suitable thermal management strategies is well established [5, 6].

In this context, interest on advanced cooling systems has revived. As indicated by Pang and Brace [7], all such strategies are characterized by the increased control that they provide on magnitudes relevant for heat transfer. This is particularly important in order to take advantage of the highest rates of heat transfer associated with nucleate boiling, mostly at high engine loads. A review of early efforts in this direction can be found in [8]. However, the generation of vapour, if not controlled, could lead to overheating with catastrophic effects [9]. In particular, precision cooling appears to be specially well suited for the incorporation of nucleate boiling without such risks $[10,11]$.

However, it has long been known that, under certain operating conditions, subcooled nucleate boiling from hot surfaces occur in many engines to some degree. An early contribution was that of Finlay et al. [12], who developed equations for forced-convective, nucleate boiling heat transfer that allowed

\footnotetext{
${ }^{*}$ Corresponding author. Tel.: +34 96 3877650, fax: +34 963877659 .

Email address: atorreg@mot .upv.es (A.J. Torregrosa)
}

them to predict correctly the relationship between heat flux and surface temperature in the liquid-cooled regions of a cylinder head. More recently, Ajotikar et al. [13] considered a simplified geometry, which allowed to establish that nucleate boiling occurs for the typical operating range of coolant mass flow rate and temperature. They were also able to detect the onset of boiling from the analysis of the fluctuating pressure within the engine cooling system.

From the point of view of engine cooling system design, subcooled boiling flow is specially attractive because vapour is present only in a thin superheated layer close to the wall, while the outer bulk flow region, where the bubbles collapse due to the subcooling, contains only liquid phase, so that no essential changes in the design are required. However, boiling flow involves many different phenomena (bubble nucleation, growth, detachment, coalescence, and collapse) taking place on very different space and time scales space and not yet fully understood or even accessible to experimental assessment [14]. Therefore, prediction of the heat flux during subcooled flow boiling in practical applications requires the use of models with considerable empirical content, which are based on two main concepts [15]: the division description method and the superposition method.

In boiling models based on the division description, the convective heat flux and boiling curves in the partially and the fully developed boiling regions, as well as the onset points of nucleate and fully developed boiling, are described separately. Among the numerous models proposed on that basis, one may highlight the one proposed by Kandlikar [16], which was later extended to comprise subcooled boiling of ethyleneglycol/water mixtures in engine-like geometries [17]. The main parameter in these models is the boiling number (i.e. the ratio 
of a dimensional estimate of the boiling velocity to the velocity of the bulk flow) and are basically designed for the fully developed boiling regime, where they exhibit a fairly good performance; however, they are reported to be quite inaccurate in the partially developed boiling regime, close to the onset of nucleate boiling [14]. However, these models have the advantage that they can be incorporated efficiently into computational fluid dynamic studies of flow in engine cooling jackets, as shown by $\mathrm{Li}$ et al. [15].

Models based on the superposition method assume that the total heat flux $q_{w}$ may be obtained from some combination of a purely convective component $q_{f c}$ and a nucleate boiling component $q_{n b}$. The most general formulation is that of the asymptotic model proposed by Steiner and Taborek [18] as

$$
q_{w}^{n}=q_{f c}^{n}+q_{n b}^{n}
$$

where $n$ is an empirical constant to be determined from experimental data. These models are attractive mainly because the correct asymptotes are provided at the transition to the nonboiling regime, where the nucleate boiling component vanishes and only the convective component remains. In the particular case of $n=1$ one recovers the simple additive model first proposed by Chen [19], which has been used almost exclusively in the automotive literature [20,14], even if its application to engine cooling passages is not totally straightforward, as the definition of a hydraulic diameter is not obvious [21].

The most comprehensive analysis of the application of the Chen model to internal combustion engines is probably that presented by Robinson et al. [20]. They stressed the importance of an accurate representation of the purely convective heat transfer accounting for the complex issues associated with the fact that the flow is undeveloped both hydrodynamically and thermally, for the sensitivity to temperature of the fluid viscosity and for surface roughness [22]. In connection with this last factor, Ramstorfer et al. [23] pointed out the importance of the surface porosity in the nucleate boiling regime, showing the potential of several surface coatings for heat flux enhancement.

More recently, [24] checked the Chen model against experimental data taken in both a flow-loop apparatus and a standard I.C. engine on subcooled flow boiling for a 50-50 ethylene glycol-water mixture [25], their results suggesting that a correction factor is required only on the forced convection component, consistently with [20]. However, it was already noted by [20] that the model fails in the boiling regime for low velocities and low inlet temperatures.

The objective of this paper is to provide additional evidence on the behavior of subcooled flow boiling in a usual engine coolant precisely at those low velocities, so that the validity of a Chen-type additive model can be assessed under those conditions. The paper is organized as follows: First, in Section 2 the experimental set-up used is described. Then, in Section 3 a version of the Chen model well adapted to low flow velocities is presented. Section 4 is devoted to the analysis of the results obtained and of the deviations observed with respect to the reference model just mentioned. Finally, in Section 5 the conclusions of the work are summarized.

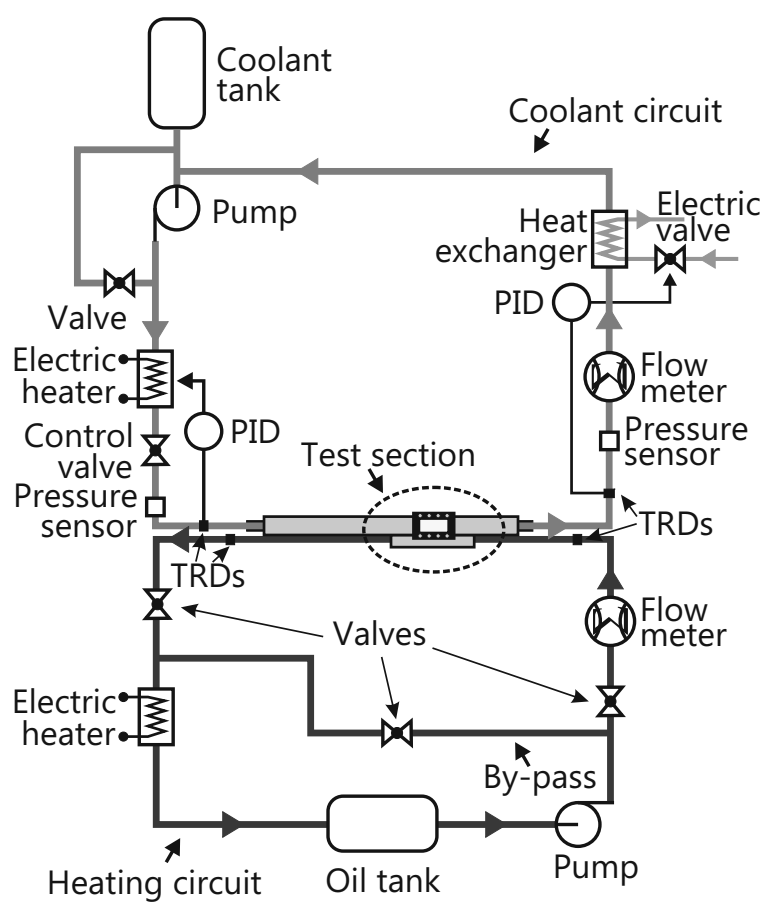

Figure 1: Schematic of the experimental set-up.

\section{Experimental set-up}

The experimental duct was designed to cause evaporation under forced flow conditions similar to those found in the cooling system of internal combustion engines. With this purpose, a system was built which consists of two separate circuits which exchange heat only at the test section. The coolant fluid under study flows through the first circuit (see top of Fig. 1), which comprises a tank, a heat exchanger, a pump and an electrical heater, so that both the temperature and the volume flow of the coolant at the inlet of the test section may be kept at the prescribed values. In the case of the volume flow, this is achieved by manually adjusting a control valve and the pump by-pass valve. In the case of the temperature, a double control strategy is used: first, the temperature of the coolant is regulated by means of a heat exchanger equipped with a solenoid valve and a PID controller that uses the measurement provided by a resistance temperature detector (RTD) located at the outlet of the test duct; then, the coolant temperature is raised by means of an electric heater located downstream of the pump and whose heat supply is regulated by means of a second PID controller whose input signal is the temperature measured by an RTD located just upstream of the test duct. Additionally, this circuit is equipped with pressure sensors allowing to determine the pressure drop across the test duct.

The second circuit (see bottom of Fig. 1) is the heating circuit, in which thermal oil is used as the heating fluid for the test duct. This heating circuit, which had previously used and validated in different applications [26, 27], includes an expansion tank, an electric oil pump, temperature and pressure control systems and different valves to allow changing the mass flow rates. Heat is supplied to the thermal oil by an electri- 

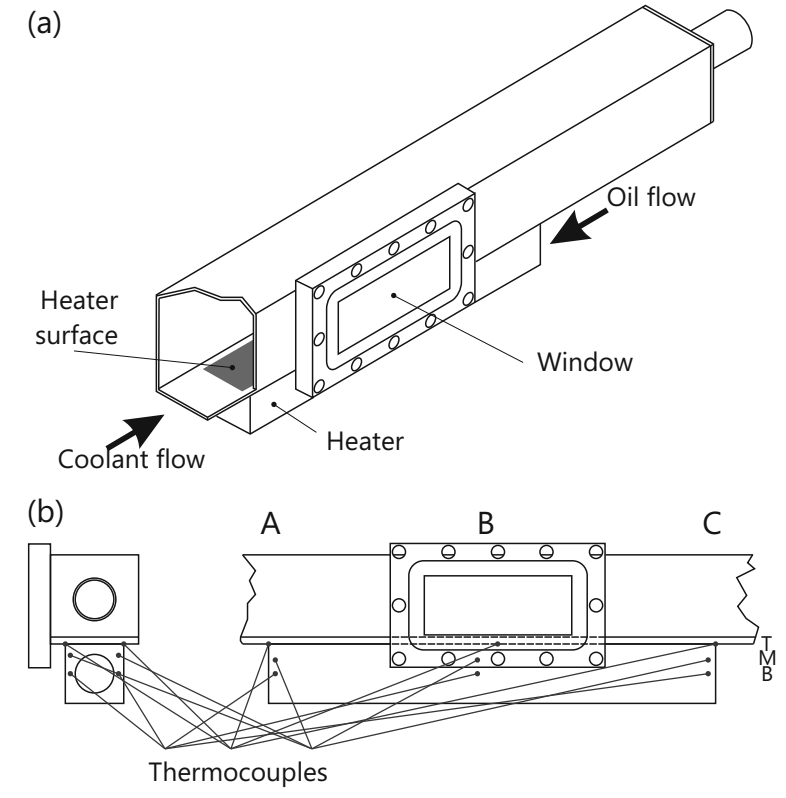

Figure 2: Test section (a) and location of the thermocouples (b).

cal heater consisting of three electrical resistances $(12.5 \mathrm{~kW}$ of nominal power each one). The system can deliver thermal oil at temperatures up to $300{ }^{\circ} \mathrm{C}$ and with volumetric flow rates up to $6.5 \mathrm{~m}^{3} / \mathrm{h}$. The temperature of the oil leaving the system is controlled by a PID that connects or disconnects the different resistors available. The flow rate is controlled by manual adjustment of the valves until the desired mass flow of oil is reached.

The test section is a horizontal rectangular duct of aluminum whose dimensions are $1000 \mathrm{~mm}$ long, $52 \mathrm{~mm}$ wide and $52 \mathrm{~mm}$ high. A transparent window was included in order to allow for the visual confirmation of the occurrence of boiling. The heating section is $40 \mathrm{~mm}$ wide and $300 \mathrm{~mm}$ long, and is located $550 \mathrm{~mm}$ away from the inlet, i.e. more than 10 hydraulic diameters from the inlet, so that the flow should be reasonably developed and it should thus be expected that bubble detachment is not significantly affected by secondary flows. With this arrangement, only part of the circulating flow within the duct is in contact with the heater surface and reaches the saturation temperature. A sketch of this measurement section is shown in Fig. 2(a).

As shown in Fig. 2(b), the surface temperature of the heater was measured with six K-type thermocouples (labeled $\mathrm{T}$ in the figure) inserted to a depth of $1 \mathrm{~mm}$ in the heating block and arranged in three sections (labeled $\mathrm{A}, \mathrm{B}$ and $\mathrm{C}$ ) along the heater. The heating block consists of a piece of aluminum with a hole in its center, and through which the thermal oil supplied by the heating circuit described above circulates. Thus, heat transfer occurs by convection from the hot oil to the heating block, and subsequently by conduction to the upper wall, which in turn transfers heat to the coolant through the heater surface. Additional thermocouples were inserted at intermediate heights (labeled $\mathrm{M}$ and $\mathrm{B}$ ) between the heater surface and the duct carrying the heating oil. Their readings, together with those of the upper

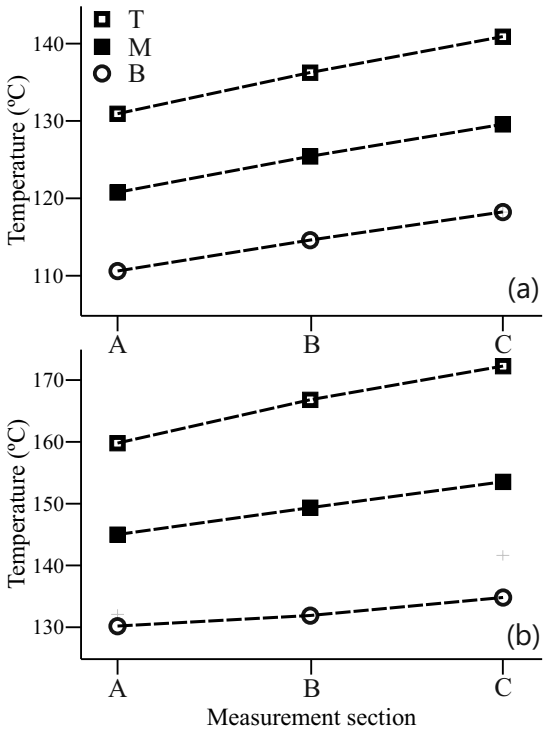

Figure 3: Raw temperature measurements: $0.1 \mathrm{~ms}^{-1}, 90{ }^{\circ} \mathrm{C}$ (a) and $0.15 \mathrm{~ms}^{-1}$, $105^{\circ} \mathrm{C}(\mathrm{a})$.

thermocouples, provided the estimate for the heat flux supplied to the coolant.

As an example of the measurement results, in Fig. 3 results for two flow and temperature conditions are shown. It can be observed that, as one could expect in view that two fluids flowing in opposite directions are exchanging heat, the temperature increases along the heater; however, the vertical temperature gradient is fairly constant along the heater, and about 50 time larger than the horizontal gradient. As a consequence, it appears that a reasonably uniform heat flow exists in the vertical direction, thus allowing for the estimation from the average vertical temperature gradient of the heat flux transmitted to the coolant.

A first validation of the rig was performed in single-phase conditions, by choosing temperatures low enough to rule out subcooled boiling and degassing. Results for three inlet fluid temperatures are shown in Fig. 4, compared with the forced convection heat flux $\tilde{q}_{f c}$, which was calculated as

$$
\tilde{q}_{f c}=h_{f c}\left(T_{w}-T_{b}\right)
$$

where $T_{w}$ is the wall temperature and $T_{b}$ is the bulk fluid temperature. The heat transfer coefficient $h_{f c}$ was computed using a Dittus-Boelter equation modified along some of the lines indicated by Robinson et al. [22] as

$$
h_{f c}=0.023 \operatorname{Re}_{l}^{0.8} \operatorname{Pr}_{l}^{0.4}\left(\frac{\mu_{b}}{\mu_{w}}\right)^{0.14}\left(\frac{k_{l}}{D_{h}}\right)
$$

Here, $k_{l}$ is the thermal conductivity of the fluid, $D_{h}$ is the hydraulic diameter, $\mu_{b}$ and $\mu_{w}$ denote the dynamic viscosity evaluated at the bulk and wall temperatures, respectively, and $\operatorname{Re}_{l}$ and $\operatorname{Pr}_{l}$ are the Reynolds number and the Prandtl number of the fluid, respectively:

$$
\operatorname{Re}_{l}=\frac{\rho_{l} u_{b} D_{h}}{\mu_{l}}, \operatorname{Pr}_{l}=\frac{\mu_{l} c_{p, l}}{k_{l}}
$$




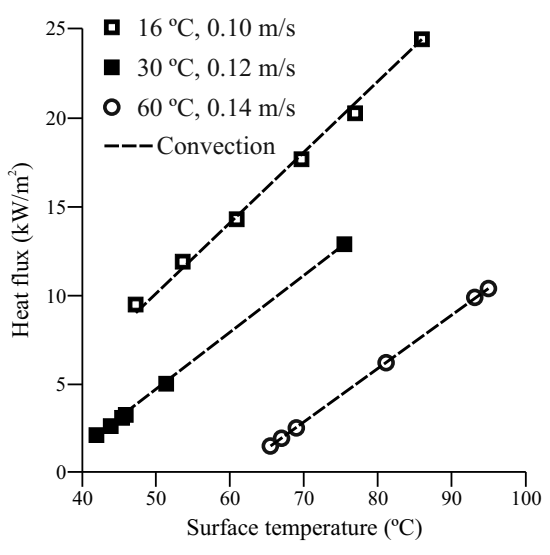

Figure 4: Single-phase validation of the set-up.

where $u_{b}$ is the bulk flow velocity and $c_{p, l}, \rho_{l}$ and $\mu_{l}$ are the specific heat, the density and the viscosity of the fluid, respectively, evaluated at its bulk temperature. The results show good agreement with the standard correlation, thus indicating the reliability of the heat flux measurement procedure.

Uncertainties in measured parameters associated with the stability provided by the set-up control and with the sensitivity of the sensors used were determined, whereas uncertainties in calculated parameters were estimated according to the error propagation techniques indicated by Moffat [28]. The results are shown in Tables 1 and 2, respectively.

\begin{tabular}{ll}
\hline \hline Parameter & Uncertainty $(\%)$ \\
\hline Temperature $\left({ }^{\circ} \mathrm{C}\right)$ & \pm 1 \\
Pressure $(\mathrm{Pa})$ & \pm 0.4 \\
Coolant flow rate $\left(\mathrm{kg} \mathrm{s}^{-1}\right)$ & \pm 0.5 \\
\hline \hline
\end{tabular}

Table 1: Measured parameters and their uncertainties.

\begin{tabular}{ll}
\hline \hline Parameter & Uncertainty $(\%)$ \\
\hline Heat transfer rate $(\mathrm{W})$ & $10.7-18.0$ \\
Heat flux $\left(\mathrm{W} \mathrm{m}^{2}\right)$ & $10.8-18.2$ \\
\hline \hline
\end{tabular}

Table 2: Calculated parameters and their uncertainties.

\section{Background of the analysis}

Accordingly with the contents of Section 1, an additive formulation as suggested by Chen [19] will be used as a reference in the subsequent analyses. The total heat flux is thus written as

$$
q_{w}=q_{f c}+q_{n b} \equiv \Phi \tilde{q}_{f c}+S \tilde{q}_{n b}
$$

Again, $\tilde{q}_{f c}$ represents the forced convection heat flux, which is computed as indicated in equations (2) to (4), with the only difference that subscript $l$ indicates now the liquid phase. The nucleate boiling heat flux $\tilde{q}_{n b}$ is given by

$$
\tilde{q}_{n b}=h_{n b}\left(T_{w}-T_{s}\right)
$$

where $T_{S}$ is the saturation temperature and the heat transfer coefficient $h_{n b}$ is computed using the correlation proposed by Forster and Zuber [29] for pool boiling heat transfer:

$$
h_{n b}=0.00122 \frac{k_{l}^{0.79} c_{p, l}^{0.45} \rho_{l}^{0.49}}{\sigma^{0.5} \mu_{l}^{0.29} l_{l g}^{0.24} \rho_{g}^{0.24}} \Delta T_{s}^{0.25} \Delta p_{s}^{0.75}
$$

where $l_{l g}$ is the latent heat of vaporization, $\sigma$ is the surface tension, $\rho_{g}$ denotes the density of the vapor phase, $\Delta T_{s}=T_{w}-T_{s}$ is the wall superheat and $\Delta p_{s}=p_{s}\left(T_{w}\right)-p_{s}\left(T_{s}\right)$ is the corresponding saturation pressure difference. Following Robinson et al. [20], all the physical properties of the liquid phase are computed taking into account its binary character, with the exception of the latent heat and the surface tension, for which the values for water as the liquid have been assumed. With respect to the gas phase, in view of the values of the boiling points (at atmospheric pressure, $100{ }^{\circ} \mathrm{C}$ for water, $197{ }^{\circ} \mathrm{C}$ for the antifreeze and $107{ }^{\circ} \mathrm{C}$ for the mixture) and the maximum temperatures achieved in the experiments, the properties of water vapor have been assumed.

The physics underlying the additive formulation is incorporated through the non-dimensional parameters $\Phi$ and $S$ in Eq. (5). Parameter $\Phi$ is a correction factor accounting for the influence of microconvective effects associated with bubble agitation. An expression for $\Phi$ that accounts for the effect of the Prandtl number was proposed by Bennett and Chen [30] as

$$
\Phi=\left(\frac{\operatorname{Pr}_{l}+1}{2}\right)^{0.444} F>1
$$

where $F$ is an enhancement factor related to the ratio of the twophase Reynolds number $\operatorname{Re}_{2 \phi}$ and the liquid Reynolds number $\operatorname{Re}_{l}$ by

$$
F=\left(\frac{\operatorname{Re}_{2 \phi}}{\operatorname{Re}_{l}}\right)^{0.8}
$$

Notice that $\Phi \sim F$ when $\operatorname{Pr}_{l} \sim 1$. In subcooled conditions it is usual to assume that $F=1$ [20], what is equivalent to neglect the effect of bubble agitation on convective heat transfer; however, such an assumption may not be justified for the low velocities considered here, mostly for relatively high wall superheats for which the void fractions become high in the vicinity of the wall [31]. Therefore, according to Chen [19] $F$ will be expressed as a function of the Martinelli parameter $X_{t t}$. That dependence was fitted by Collier [32] as

$$
F= \begin{cases}2.35\left(X_{t t}^{-1}+0.213\right)^{0.736} & : X_{t t}^{-1}>0.1 \\ 1 & : X_{t t}^{-1} \leq 0.1\end{cases}
$$

Here, the Martinelli parameter is given by

$$
X_{t t}=\left(\frac{1-x}{x}\right)^{0.9}\left(\frac{\rho_{g}}{\rho_{l}}\right)^{0.5}\left(\frac{\mu_{l}}{\mu_{g}}\right)^{0.5}
$$

where $\mu_{g}$ is the viscosity of the vapor phase and $x$ is the vapor quality, of which an effective value for subcooled boiling is computed here following Kandlikar [16] as

$$
x=-c_{p, l}\left(T_{s}-T_{b}\right) / l_{l g}
$$




\begin{tabular}{ccccc}
\hline \hline$p$ (bar) & $\dot{V}\left(\mathrm{~m}^{3} \mathrm{~h}^{-1}\right)$ & $u_{b}(\mathrm{~m} / \mathrm{s})$ & $T_{i}\left({ }^{\circ} \mathrm{C}\right)$ & $T_{s}\left({ }^{\circ} \mathrm{C}\right)$ \\
\hline 1.82 & 1.0 & 0.10 & 90 & 126.1 \\
1.87 & 1.5 & 0.15 & 90 & 127.0 \\
1.86 & 2.0 & 0.20 & 90 & 126.9 \\
1.99 & 3.0 & 0.30 & 90 & 129.1 \\
1.93 & 1.0 & 0.10 & 105 & 128.1 \\
1.94 & 1.5 & 0.15 & 105 & 128.2 \\
1.97 & 2.0 & 0.20 & 105 & 128.7 \\
2.00 & 3.0 & 0.30 & 105 & 129.2 \\
\hline \hline
\end{tabular}

Table 3: Experimental matrix considered.

Regarding the suppression factor $S$, which accounts for the observed decrease in nucleate boiling activity when the flow velocity increases, the analytical best-fitting expression proposed by Butterworth and used almost universally (see, for instance, [14]) was used:

$$
S=\frac{1}{1+2.53 \times 10^{-6} \operatorname{Re}_{2 \phi}^{1.17}}<1
$$

so that $S$ does not exhibit any explicit dependence on the Prandtl number.

\section{Results and discussion}

\subsection{Experimental plan}

A series of experimental tests was carried out in order to obtain a representative data set covering a sufficiently wide range of operating conditions. The measurements were carried out using a mixture of $50 \%$ water and $50 \%$ ethylene glycol (volume percentages). For the coolant flow, values of $1 \mathrm{~m}^{3} \mathrm{~h}^{-1}, 1.5$ $\mathrm{m}^{3} \mathrm{~h}^{-1}, 2 \mathrm{~m}^{3} \mathrm{~h}^{-1}$ and $3 \mathrm{~m}^{3} \mathrm{~h}^{-1}$ were considered, whereas for the temperature of the coolant at the inlet of the heating circuit values of $90{ }^{\circ} \mathrm{C}$ and $105{ }^{\circ} \mathrm{C}$ were taken. The temperature of the thermal oil used to rise the temperature of the heating element in the test duct was varied between $100{ }^{\circ} \mathrm{C}$ and $280{ }^{\circ} \mathrm{C}$ at increments of $40{ }^{\circ} \mathrm{C}$, whereas its flow rate was maintained at 1.92 $\mathrm{m}^{3} \mathrm{~h}^{-1}$.

The configuration of the conduit allows coolant fluid velocities within the range $0.1 \mathrm{~ms}^{-1} \leq u_{b} \leq 0.3 \mathrm{~ms}^{-1}$ with Reynolds number values ranging from 4300 to 17800 . The operating pressure at which measurements were taken was within the range $1.82 \leq p \leq 2.0$ bar. Table 3 summarizes the relevant conditions for all the experiments.

\subsection{Comparison with reference model}

As usual in the literature, the results obtained for the heat flux are shown as a function of the wall temperature (in the present case, the temperature of the heater element). In Fig. 3 results are shown for different flow conditions: four different flow velocities $\left(0.1 \mathrm{~ms}^{-1}, 0.15 \mathrm{~ms}^{-1}, 0.2 \mathrm{~ms}^{-1}\right.$ and $\left.0.3 \mathrm{~ms}^{-1}\right)$ and two fluid inlet temperatures $\left(90{ }^{\circ} \mathrm{C}\right.$ and $\left.105{ }^{\circ} \mathrm{C}\right)$. The values provided by the reference model previously described in Section 3 are shown along with the experimental data.
As a first comment, the existence of the two distinct regimes can be clearly seen in the plots: the pure convection, and that related to the onset of boiling, with the transition between the two regimes occurring when the wall temperature reaches a certain value above the saturation temperature of the fluid, which depends on the inlet temperature. This provides a first qualitative check of the quality of the measurements. Additionally, the good agreement observed between the measured flux and the reference model for the purely convective regime (i.e. without any wall superheat) allows to extract two conclusions: first, it is confirmed that, under these conditions, there is no need to introduce any correction to account for the influence of bubble motion on the flow field near the wall; secondly, these results provide a second and quantitative check for the quality of the measurements, thus suggesting that the fluxes measured under subcooled boiling conditions should have a similar quality.

As a general confirmation of the trends observed, it may be interesting to analyze briefly the effects of inlet temperature and flow rate. With respect to the inlet temperature, the curves corresponding to $105^{\circ} \mathrm{C}$ are shifted towards high wall temperatures, as it should obviously be expected for both the purely convective regime and the subcooled boiling, in the first case due to the lower temperature difference between fluid and wall, and in the second case due to the lower difference between the bulk and the saturation temperatures, so that the heat flux required for the onset of boiling is also smaller.

In the partially developed boiling regime at lower wall superheats, the bulk flow rate affects the heat transfer significantly: the onset of nucleate boiling is shifted to higher wall superheats for higher flow rates [14]. Regarding the influence of the flow velocity, the expected increase in the purely convective heat flux with flow speed is observed, as well as the expected shift to higher wall temperatures of the boiling onset temperature associated with the higher heat flux required, as Chen correctly interpreted by introducing the suppression factor $S$.

With regard to the agreement between the measured results and those obtained from the reference model in the subcooled boiling regime, one can observe a reasonable approximation to the experimental data for an inlet temperature of $90{ }^{\circ} \mathrm{C}$, this approximation being better as the flow velocity increases. This trend with velocity is also apparent in the curves corresponding to an inlet temperature of $105^{\circ} \mathrm{C}$. In general, the deviations in wall temperature for a given heat flux lie reasonably within the experimental accuracy; however, when considering the potential of nucleate boiling for increasing the heat flux, it appears that the model gives systematically heat flux values higher than those measured, which. For the two lowest velocities this is clearly related to the slope change observed in the experimental results, which could be interpreted, following [14] as an indication that the conditions may be close to the onset of partial film boiling. In any case, it appears that the model yields acceptable results for wall temperatures below $135{ }^{\circ} \mathrm{C}$ regardless of the inlet temperature considered, even if it is based on a method originally proposed for saturated annular flows in vertical tubes. It is therefore interesting to consider also some prediction method specifically developed for subcooled flow boiling, such as that proposed by Gungor and Winterton [33] in order to evaluate the 

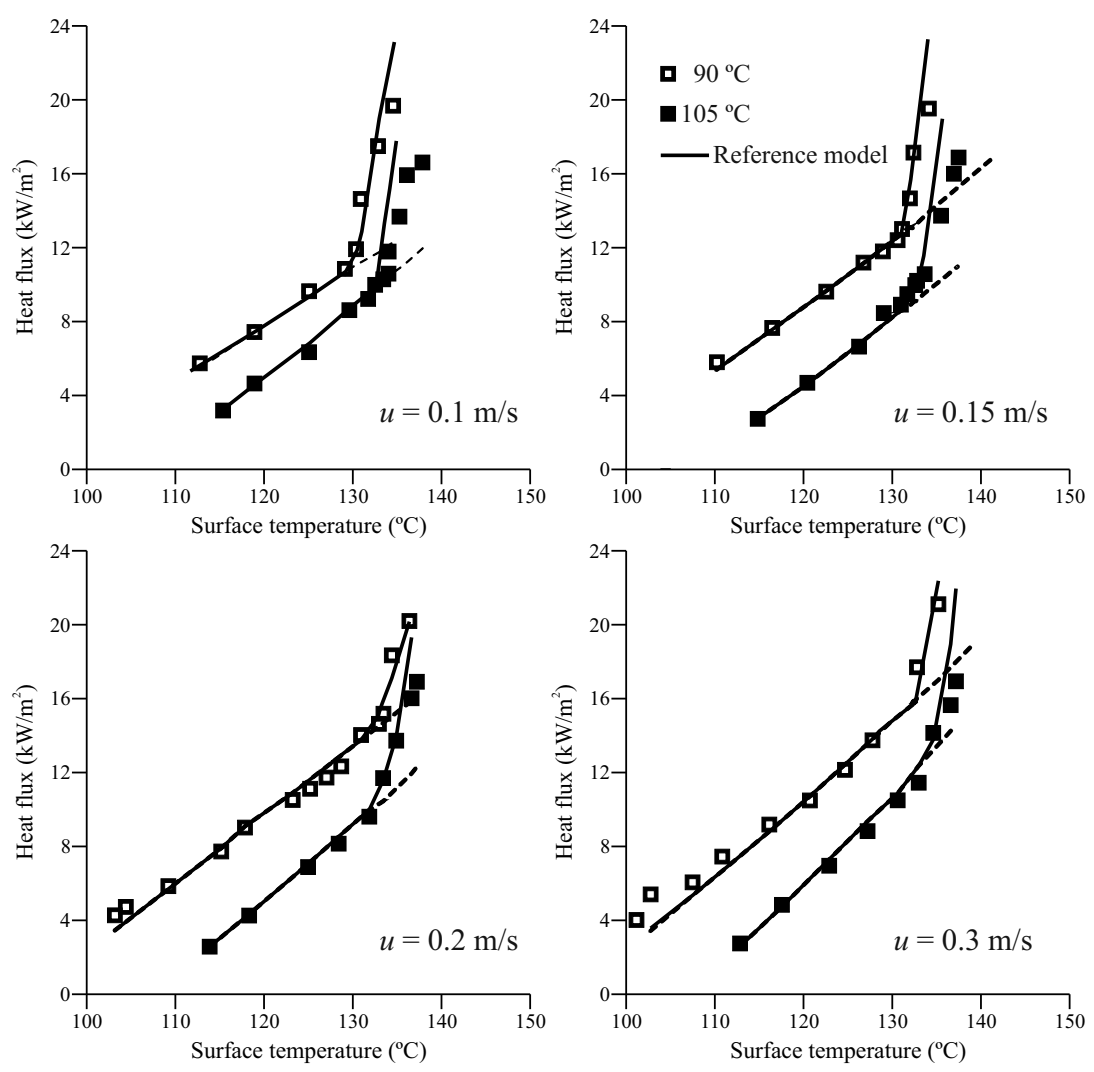

Figure 5: Comparison of measurement results with the reference model for different flow velocities.

quality of the results provided by the reference model chosen.

The correlation proposed by Gungor and Winterton [33] has the same basic structure as in equation (5). The forced convection term $\tilde{q}_{f c}$ as given by equations (3) and (4), but different expressions for the $\Phi, S$ and $\tilde{q}_{n b}$ are considered. The correction factor $\Phi$ is now given by

$$
\Phi=1+24000 \mathrm{Bo}^{1.16}+1.37 X_{t t}^{-0.86}
$$

where $\mathrm{Bo}=q /\left(l_{l g} G\right.$ is the boiling number $(G$ is the total mass flow), and the Martinelli parameter is again given by equation (11). The suppression factor is now computed as

$$
S=\frac{1}{1+1.15 \times 10^{-6} \Phi^{2} \operatorname{Re}_{l}^{1.17}}
$$

and the nucleate boiling heat flux $\tilde{q}_{n b}$ is given by equation (6) but now the corresponding heat transfer coefficient $h_{n b}$ for pool boiling is computed with the correlation proposed by Cooper [34]:

$$
h_{n b}=55 p_{r}^{0.12}\left(-\log _{10} p_{r}\right)^{-0.55} M^{-0.5} q^{0.67}
$$

where $p_{r}$ is the reduced pressure, $M$ is the molecular weight of the coolant and $q$ is the heat flux (so that some iteration is required).

Some representative examples of the results obtained are shown in Fig. 6, where it can be observed that, for the particular measurement conditions considered here, the performance of the Gungor-Winterton correlation, while within a deviation

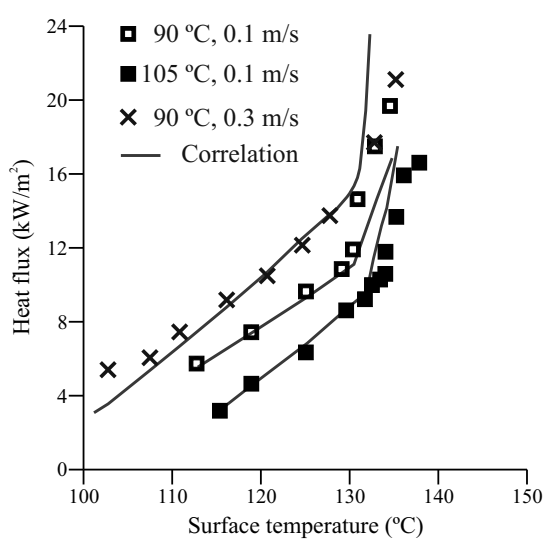

Figure 6: Comparison of measurement results with the Gungor-Winterton correlation for three relevant cases.

of 25\% [33], is either similar (as in the case with $u=0.1 \mathrm{~ms}^{-1}$ and inlet temperature of $105{ }^{\circ} \mathrm{C}$ ) or poorer than that of the reference model chosen; most notably, while the reference model overpredicts systematically the heat flux, the corresponding behavior of the Gungor-Winterton correlation is far more erratic. Therefore, the reference model described in the previous section which was considered for further analysis.

\subsection{Analysis of the suppression factor}

In order to get additional information on the deviations observed and to explore the possibilities of extending the appli- 

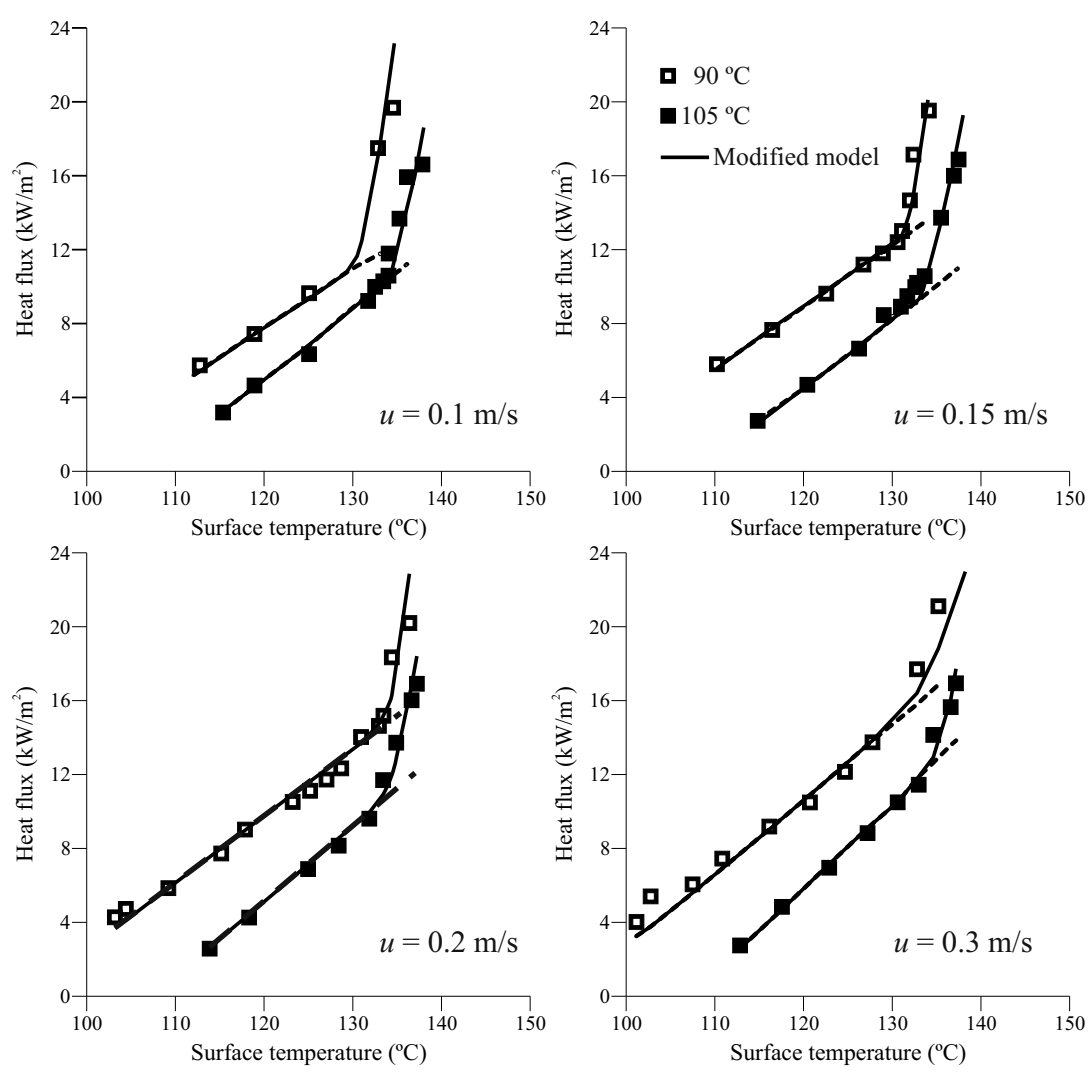

Figure 8: Comparison of measurement results with the modified correlation for different flow velocities.

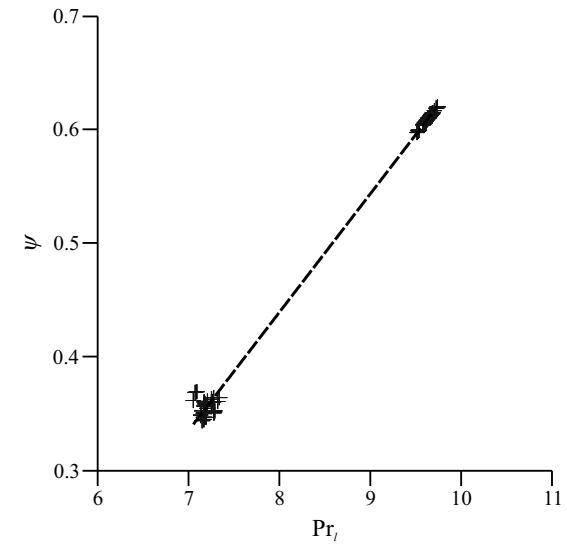

Figure 7: Dependence of the correction parameter $\psi$ on the Prandtl number Py and linear fit. cability of the model to all the measured conditions, among the different aspects of the model it was considered that the computation of the suppression factor from Eq. (13) demanded additional analyses. Therefore, following the methodology outlined by Liu and Garimella [35], an expression for the suppression factor was derived from the measured data through a regression analysis. Assuming that the measured heat flux $q_{w}^{\text {exp }}$ obeys Eq. (2), one has

$$
q_{w}^{\exp }=\Phi^{\exp } \tilde{q}_{f c}+S^{\exp } \tilde{q}_{n b}
$$

where $\tilde{q}_{f c}$ and $\tilde{q}_{n b}$ are given by Eq. (3) and Eq. (6), respectively. Assuming now that $\Phi^{\text {exp }}$ is duly represented by $\Phi$ as expressed in equations (8) to (12), and that the experimental suppression factor can be written as $S$ exp $=\psi S$, where $S$ is given by Eq. (13) and $\psi$ is an adjustment parameter to be identified, the equation to be fitted to the experimental data is finally

$$
\psi=\frac{q_{w}^{\exp }-\Phi \tilde{q}_{f c}}{S \tilde{q}_{n b}}
$$

An extensive analysis was performed on the eventual dependence of the adjustment parameter $\psi$ on all the non-dimensional groups relevant for the problem, the only significant dependence found being that on the Prandtl number $\operatorname{Pr}_{l}$. The corresponding results are shown in Fig. 7, where a clear and significant dependence may be observed, with two distinct clouds of points around the Pr values corresponding to the two inlet temperatures considered. 
It is likely that such a dependence in the suppression factor is related to the influence on the thermal boundary layer temperature profile of bubble motion, which in turn is affected by the velocity field in the velocity boundary layer, whose thickness is approximately proportional to $\left(k_{l} / h\right) \operatorname{Pr}$.

Even if the data available are not sufficiently wide to allow for a proper representation of the observed influence, in order to get some first-order estimate of the magnitude of the effect in the experimental conditions considered the results were fitted as $\psi=0.104 \operatorname{Pr}_{l}-0.4$ with a squared correlation coefficient of $R^{2}=0.99$.

As a final check of the results from this analysis, in Fig. 8 the same representation as in Fig. 5 is given with the model including the modified suppression factor. It can be observed that an acceptable agreement is now obtained, even for the highest heat fluxes measured, thus indicating the interest of this possibility for practical applications to engine cooling systems.

\section{Conclusions}

Experiments on subcooled boiling flow in temperature conditions close to those of the cooling jacket of an internal combustion engine were conducted. The focus of the study was on low velocities that may appear locally in certain engine cooling passages when advanced thermal management strategies are used, and for which there appears to be little experimental evidence.

An experimental rig allowing for a suitable control of the coolant flow an temperature was built, and measurements were taken at two representative inlet temperatures and four coolant velocities. The results were initially analyzed by comparison with a reference model in which, according with the available literature, the expressions used for the different contributions to the total heat flux were well adapted to the measurement conditions.

From the analysis performed, it was concluded that, while the reference model provided reasonable results for wall temperatures below $135{ }^{\circ} \mathrm{C}$, there appeared noticeable discrepancies at higher wall temperatures, mostly in the case of the highest inlet coolant temperature. Assuming that the origin of the deviations observed was on the expression used for the suppression factor, a regression analysis was performed that indicated a significant influence of the Prandtl number on the suppression factor. Incorporation into the model of a first estimate of that influence produced a noticeable improvement in its agreement with the experimental data, thus suggesting that an additive model modified along these lines may be useful for practical engine cooling applications.

\section{Acknowledgments}

This work has been supported by Ministerio de Ciencia e Innovación through grant TRA2010-16205. O. Cornejo is indebted to Senacyt Panamá for their support.

\section{Nomenclature}

\begin{tabular}{|c|c|c|}
\hline Bo & Boiling number $\ldots \ldots \ldots$ & $\begin{array}{l}{[-]} \\
{\left[\mathrm{J} \mathrm{kg}^{-1} \mathrm{~K}^{-1}\right]}\end{array}$ \\
\hline & specific heat ...... & \\
\hline $\begin{array}{l}D_{h} \\
F\end{array}$ & $\begin{array}{l}\text { hydraulic diameter . } \\
\text { enhancement factor }\end{array}$ & {$[\mathrm{m}]$} \\
\hline$G$ & mass flow .......... & $\begin{array}{l}{[-]} \\
{\left[\mathrm{kg} \mathrm{s}^{-1}\right]}\end{array}$ \\
\hline & heat transfer coefficient & {$\left[\mathrm{W} \mathrm{m}^{-2} \mathrm{~F}\right.$} \\
\hline & thermal conductivity ...... & {$\left[\mathrm{W} \mathrm{m}^{-1} \mathrm{~K}^{-1}\right]$} \\
\hline & latent heat & {$\left[\mathrm{J} \mathrm{kg}^{-1}\right]$} \\
\hline$M$ & molecular weight . & {$[-]$} \\
\hline$n$ & empirical constant & {$[-]$} \\
\hline$p$ & pressure & {$[\mathrm{Pa}]$} \\
\hline $\operatorname{Pr}$ & Prandtl number..$\ldots \ldots \ldots$ & {$[-]$} \\
\hline 4 & specific heat transfer rate .. & {$\left[\mathrm{W} \mathrm{m}^{-2}\right]$} \\
\hline $\operatorname{Re}$ & Reynolds number .. & {$[-]$} \\
\hline$S$ & suppression factor $\ldots$ & {$[-]$} \\
\hline$T$ & temperature $\ldots \ldots \ldots \ldots$. & {$\left[{ }^{\circ} \mathrm{C}\right]$} \\
\hline$u$ & velocity $\ldots \ldots \ldots \ldots$ & {$\left[\mathrm{m} \mathrm{s}^{-1}\right]$} \\
\hline 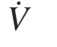 & volumetric flow rate $\ldots$... & {$\left[\mathrm{m}^{3} \mathrm{~s}^{-1}\right]$} \\
\hline$X_{t t}$ & Martinelly parameter ...... & {$[-]$} \\
\hline & vapor quality .. & {$[-]$} \\
\hline
\end{tabular}

Greek symbols

$\begin{array}{lll}\mu & \text { dynamic viscosity } \ldots \ldots \ldots & {\left[\mathrm{kg} \mathrm{m}^{-1} \mathrm{~s}^{-1}\right]} \\ \rho & \text { mass density } \ldots \ldots \ldots \ldots \ldots & {\left[\mathrm{kg} \mathrm{m}^{-3}\right]} \\ \Phi & \text { correction factor } \ldots \ldots \ldots \ldots & {[-]} \\ \psi & \text { adjustment parameter } \ldots \ldots & {[-]} \\ \sigma & \text { surface tension } \ldots \ldots \ldots \ldots & {\left[\mathrm{kg} \mathrm{s}^{-2}\right]}\end{array}$

Superscripts
exp experimental
from standard correlation

\section{Subscripts \\ $2 \phi$ two-phase \\ $b$ bulk \\ $f c$ forced convection \\ $g \quad$ vapor phase \\ $l \quad$ liquid phase \\ $\lg$ vaporization \\ $n b$ nucleate boiling \\ $p$ constant pressure \\ $r$ reduced \\ $s$ saturation \\ $w \quad$ wall}

\section{References}

[1] W. Knecht, Diesel engine development in view of reduced emission standards, Energy 33(2) (2008) 264-271.

[2] A. M. K. P. Taylor, Science review of internal combustion engines, Energy Policy 36(2) (2008) 4657-4667.

[3] Z. J. Sroka, Some aspects of thermal load and operating indexes after downsizing for internal combustion engine, J. Therm. Anal. Calorim. 110(1) (2012) 51-58.

[4] E. Sher, I. Sher, Theoretical limits of scaling-down internal combustion engines, Chemical Engineering Science 66(3) (2011) 260-267. 
[5] A. J. Torregrosa, P. Olmeda, J. Martín, B. Degraeuwe, Experiments on the influence of inlet charge and coolant temperature on performance and emissions of a di diesel engine, Exp. Therm. Fluid Sci. 30(7) (2006) 633-641.

[6] A. J. Torregrosa, A. Broatch, P. Olmeda, C. Romero, Assessment of the influence of different cooling system configurations on engine warm-up, emissions and fuel consumption, Int. J. Automot. Technol. 9(4) (2008) 447-458.

[7] H. H. Pang, C. J. Brace, Review of engine cooling technologies for modern engines, Proc. Inst. Mech. Eng., Part D 218(11) (2004) 1209-1215.

[8] S. Zidat, J. Jullien, D. Gentile, Refroidissement par ébullitioncondensation: Etat de 1'art dans le domaine des moteurs, Rev. Gen. Therm. 30(354-55) (1991) 381-387.

[9] N. A. F. Campbell, J. G. Hawley, Predicting critical heat flux as a precursor to a boiling-based ic engine-cooling strategy, Journal Of The Institute Of Energy 76(506) (2003) 22-28.

[10] N. A. F. Campbell, D. G. Tilley, S. A. MacGregor, L. Wong, Incorporating nucleate boiling in a precision cooling strategy for combustion engines, SAE Paper 971791 (1997).

[11] K. Robinson, N. A. F. Campbell, J. G. Hawley, D. G. Tilley, A review of precision engine cooling, SAE Paper 1999-01-0578 (1999).

[12] I. C. Finlay, D. Harris, D. J. Boam, B. I. Parks, Factors influencing combustion chamber wall temperatures in a liquid cooled, automotive spark ignition engine, Proc. Inst. Mech. Eng., Part D 199(3) (1985) 207-214.

[13] N. Ajotikar, B. Eggart, S. A. Miers, Nucleate boiling identification and utilization for improved internal combustion engine efficiency, in: Proc. ASME Internal Combustion Engine Division Fall Technical Conference, 2010, pp. 949-958.

[14] H. Steiner, G. Brenn, F. Ramstorfer, B. Breitschädel, Increased cooling power with nucleate boiling flow in automotive engine applications, in: M. Chiaberge (Ed.), New trends and developments in automotive system engineering, InTech, 2011, pp. 249-272.

[15] Z. Li, R. H. Huang, Z. W. Wang, Subcooled boiling heat transfer modelling for internal combustion engine applications, Proc. Inst. Mech. Eng., Part D 226(3) (2012) 301-311.

[16] S. Kandlikar, Heat transfer characteristics in partial boiling, fully developed boiling, and significant void flow regions of subcooled flow boiling, J. Heat Transfer 120(2) (1998) 395-401.

[17] S. Kandlikar, M. Bulut, An experimental investigation on flow boiling of ethylene-glycol/water mixtures, J. Heat Transfer 125(2) (2003) 317-325.

[18] D. Steiner, J. Taborek, Flow boiling heat transfer in vertical tubes correlated by an asymptotic model, Heat Transfer Eng. 13(2) (1992) 43-69.

[19] J. C. Chen, Correlation for boiling heat transfer to saturated fluids in convective flow, I\&EC Process Des. Dev. 5(3) (1966) 322-329.

[20] K. Robinson, J. G. Hawley, N. A. F. Campbell, Experimental and modeling aspects of flow boiling heat transfer for application to internal combustion engines, Proc. Inst. Mech. Eng., Part D 217(10) (2003) 877-889.

[21] M. Cardone, A. Senatore, D. Buono, M. Polcino, G. De Angelis, P. Gaudino, A model for application of chens boiling correlation to a standard engine cooling system, SAE Paper 2008-01-1817 (2008).

[22] K. Robinson, J. Hawley, G. P. Hammond, N. J. Owen, Convective coolant heat transfer in internal combustion engines, Proc. Inst. Mech. Eng., Part D $217(2)$ (2003) 133-146.

[23] F. Ramstorfer, H. Steiner, G. Brenn, C. Kormann, F. Rammer, Subcooled boiling flow heat transfer from plain and enhanced surfaces in automotive applications, J. Heat Transfer 130(1) (2008) 011501

[24] H. S. Lee, Heat transfer predictions using the chen correlation on subcooled flow boiling in a standard ic engine, SAE Paper 2009-01-1530 (2009).

[25] H. S. Lee, A. T. O'Neill, Forced convection and nucleate boiling on a small flat heater in a rectangular duct: experiments with two working fluids, a 50-50 ethylene glycol-water mixture, and water, Proc. Inst. Mech. Eng., Part D 223(2) (2009) 203-219.

[26] A. J. Torregrosa, A. Broatch, P. Olmeda, J. Martín, A contribution to film coefficient estimation in piston cooling galleries, Exp. Therm. Fluid Sci. 34(2) (2010) 142151.

[27] J. R. Serrano, P. Olmeda, A. Páez, F. Vidal, An experimental procedure to determine heat transfer properties of turbochargers, Meas. Sci. Technol. 21(3) (2010) 035109.

[28] R. J. Moffat, Describing uncertainties in experimental results, Exp. Therm. Fluid Sci. 1(1) (1988) 3-17.
[29] H. K. Forster, N. Zuber, Dynamics of vapor bubbles and boiling heat transfer, AIChE J. 1(4) (1955) 531-535.

[30] D. L. Bennett, J. C. Chen, Forced convective boiling in vertical tubes for saturated pure components and binary mixtures, AIChE J. 26(3) (1980) 454-461.

[31] F. Ramstorfer, H. Steiner, G. Brenn, Modeling of the microconvective contribution to wall heat transfer in subcooled boiling flow, Int. J. Heat Mass Transfer 51(15-16) (2008) 4069-4082.

[32] J. G. Collier, Forced convective boiling, in: A. E. Bergles, J. G. Collier, J. M. Delhaye, G. F. Hewitt, F. Mayinger (Eds.), Two phase flow and heat transfer in the power and process industries, Hemisphere, 1981.

[33] K. E. Gungor, R. H. S. Winterton, A general correlation for flow boiling in tubes and annuli, Int. J. Heat Mass Transfer 28(3) (1986) 351-358.

[34] M. G. Cooper, Heat flow rates in saturated nucleate pool boiling - a wide-anging examination using reduced properties, Adv. Heat Transfer 16 (1984) 157-239.

[35] D. Liu, S. V. Garimella, Flow boiling heat transfer in microchannels, J. Heat Transfer 129(10) (2007) 1321-1332. 